5th International Science Congress \& Exhibition APMAS2015, Lykia, Oludeniz, April 16-19, 2015

\title{
The $\mathrm{NO}_{2}$ Sensing Properties of the Sensors Done with Nano-Tetrapods
}

\author{
F.R. TULUN ${ }^{a, *}$, S. ÖZTÜRK ${ }^{b}$, Z.Z. ÖZTÜRK ${ }^{b}$ \\ ${ }^{a}$ Material Science and Engineering, Gebze Institute of Technology, Çayırova Mh., Gebze Yüksek Teknoloji Enst., \\ Çayırova/Gebze/Kocaeli/Turkey \\ ${ }^{b}$ Physics, Gebze Institute of Technology, Çayırova Mh., Gebze Yüksek Teknoloji Enst., \\ Çayırova/Gebze/Kocaeli/Turkey
}

\begin{abstract}
In this work we have studied the NO2 sensing properties of the sensors with tetrapods. The tetrapods that were used in the production were obtained by CVD route, and their structural analysis was carried out using SEM, $\mathrm{XRD}$ and EDX methods. The sensors were produced by a different method that the one mentioned in our another work, and additional electrical $I-V$ characterization was carried out. As well as in the previous work the sensors were tested for $50 \mathrm{ppm}$ sensitivity, by using computer controlled gas flux system, in $\mathrm{NO}_{2}$ at $200{ }^{\circ} \mathrm{C}$, and in ambient air to model the normal working conditions more closely. It was found that the sensors have a good sensitivity to the $\mathrm{NO}_{2}$ gas. All of the sensors showed a great reversibility and it was found that the recovery time was perfectly low. After this experiment the same sensors were tested with other different gases for several times. And no other problems in sensing ability were seen.
\end{abstract}

DOI: 10.12693/APhysPolA.129.797

PACS/topics: 81.07.-b, 81.16.-c, 81.10.Fq, 07.07.Df, 81.10.St

\section{Introduction}

Due to a direct and wide bandgap $(3.37 \mathrm{eV}$ at room temperature), $\mathrm{ZnO}$ is considered to be a very important semiconductor. Due to its various properties like wide band gap [1, 2], good thermal and chemical stability $[3,4]$, antimicrobial $[5,6]$, photocatalitic and sensor $[7,8]$ features, it is a promising material for potential future applications [9]. One of the expected application of $\mathrm{ZnO}$ is in the area of biocompatibile gas sensors which can be used to detect gases like $\mathrm{NO}_{2}$, hazardous for the nature and human health.

In the present work we have synthesized randomly precipitated and perfectly formed $\mathrm{ZnO}$ tetrapods in APCVD system in a constant oxygen flow at $1200^{\circ} \mathrm{C}$. The nanostructures were characterized from the aspect of nanostructure, XRD and EDX characteristics. It was found that the structures were perfect pure wurtzite crystal tetrapods. The length of the structures was measured to be approximately 10 to $18 \mu \mathrm{m}$ and it was found that the thickness of the legs was between approximately $140 \mathrm{~nm}$ and $40 \mathrm{~nm}$. The tetrapods were used to produce a gas sensor by trying a novel method. The obtained sensor has been able to perfectly detect presence of $50 \mathrm{ppm}$ of $\mathrm{NO}_{2}$ in the air at $200^{\circ} \mathrm{C}$.

\section{Experimental}

We started the experiments by preparing the Si substrates for the APCVD system. As the first step $\mathrm{Si}$

*corresponding author; e-mail: fatma.ozmr@gmail.com substrates were cleaned in sonic vibrator in acetone (99.999\%) for $10 \mathrm{~min}$ and in UP water for $10 \mathrm{~min}$ for 5 times. Then $\mathrm{ZnO}$ tetrapod-shaped nanostructures were grown on the substrates using an APCVD system. The nano-tetrapods were synthesized on $\mathrm{Si}$ (111) substrates in a horizontal tube furnace system, under the constant flow of oxygen and argon, used as the carrier gas. Pure $\mathrm{ZnO}$ (99.9\%, $0.03 \mathrm{~g}$ ) was placed inside the furnace system and the Si substrate was placed in the precipitation region of the system. To synthesize the $\mathrm{ZnO}$, the zinc source material was vaporized and precipitated on the Si substrate at atmospheric pressure under flow of $\mathrm{Ar}(99.999 \%)$ at $120 \mathrm{sccm}$ and $\mathrm{O}_{2}(99.999 \%)$ at $5 \mathrm{sccm}$ gas mixture. The temperature of the system was gradually increased to $1200{ }^{\circ} \mathrm{C}$ and than cooled down to room temperature.

As the third step the $\mathrm{Si}$ substrates for the sensors were prepared in a thermal evaporator system using $\mathrm{Au}(99.999 \%)$. The gold was deposited through a mask which allows to make the heating and conducting network for the sensors. The deposited film thickness was $20 \mathrm{~nm}$. After the $\mathrm{Au}$ deposition, the samples were cleaned by a subsequent rinsing in acetone, ethanol, and water. As the forth step, the obtained tetrapods were mixed with ethanol and applied on the surface of the $\mathrm{SiO}_{2}$ using a pasteur pipette. Then the substrates were dried at $100^{\circ} \mathrm{C}$ for 12 hours.

As fifth and the last step the sensitivity measurements were carried out in a computer controlled closed gas system, under $150 \mathrm{sccm}$ of ambient dry air and $50 \mathrm{sccm}$ of $\mathrm{NO}_{2}$ gas at $200{ }^{\circ} \mathrm{C}$. The gas sensing properties of the tetrapods were tested by measuring the resistance change due to the gas adsorbed on their surface. 


\section{Results and discussion}

The prepared $\mathrm{ZnO}$ tetrapods were examined in a SEM system and analyzed with EDX. We observed nanosized tetrapods had a morphology very similar to a symmetric tetrapod system. The fact that breaks the symmetry is the angle between the legs of the tetrapods, which is assumed to be caused of the randomness inside the flow system. The length of the structures were measured to be approximately 10 to $18 \mu \mathrm{m}$, as can be seen in SEM image (Fig. 1). The thickness of the legs of the tetrapods was found to be between $40 \mathrm{~nm}$ and $140 \mathrm{~nm}$. To determine the content of the tetrapods, the nanoparticles were studied using EDX system. Figure 2 shows that EDX measurement contains only the characteristic peaks of $\mathrm{Zn}$ and $\mathrm{O}$, which demonstrates that tetrapods do not contain impurities.

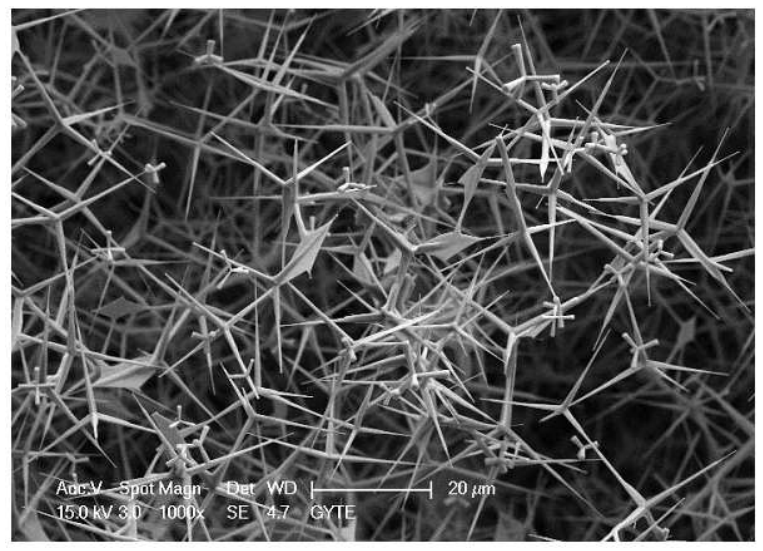

Fig. 1. SEM of the nano-tetrapods.

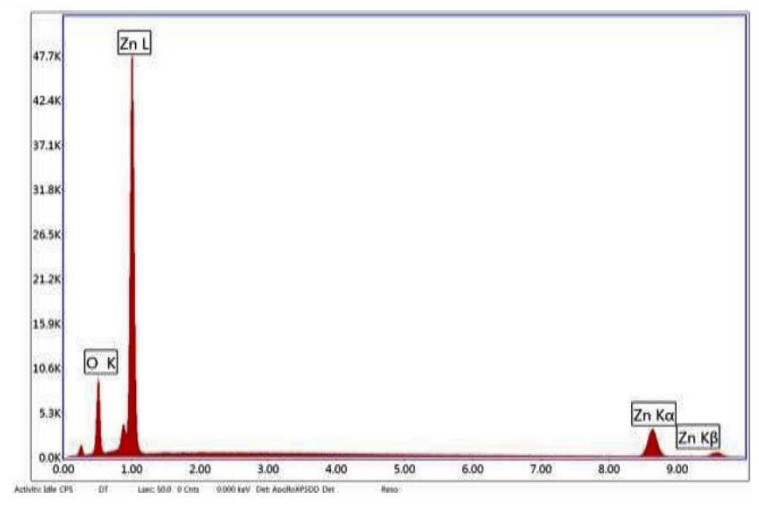

Fig. 2. EDX spectrum of the nano-tetrapods.

Figure 3 depicts the XRD diagram of the nano tetrapods. All diffraction peaks well match with the wurtzite hexagonal structure of $\mathrm{ZnO}$, thus confirming that the material of the tetrapods is zinc oxide.

The sensors were characterized in terms of $\mathrm{NO}_{2}$ sensing properties. The $\mathrm{NO}_{2}$ gas was introduced into the gas chamber by using a syringe $(50 \mathrm{sccm})$. Because of the good mobility of $\mathrm{NO}_{2}$ and high temperature inside the closed gas cell, no additional actions were needed to obtain a homogeneous gas distribution.

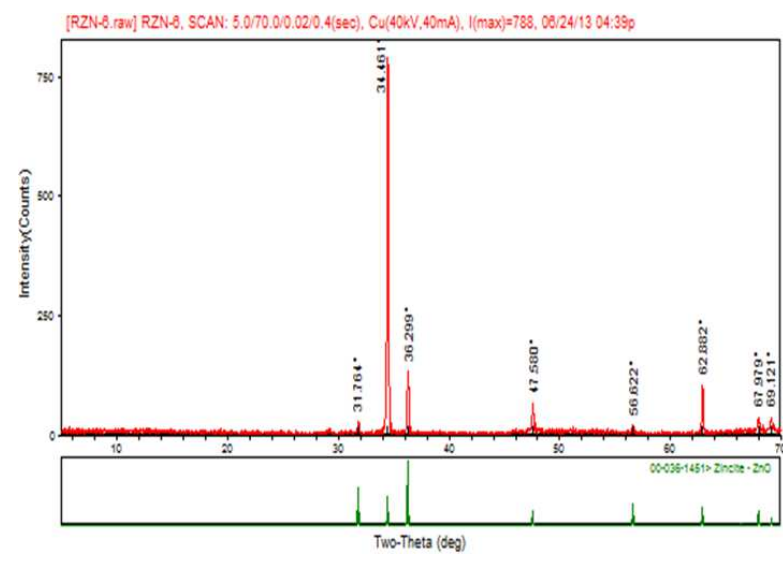

Fig. 3. XRD diagram of the nano-tetrapods used in the studied sensor.

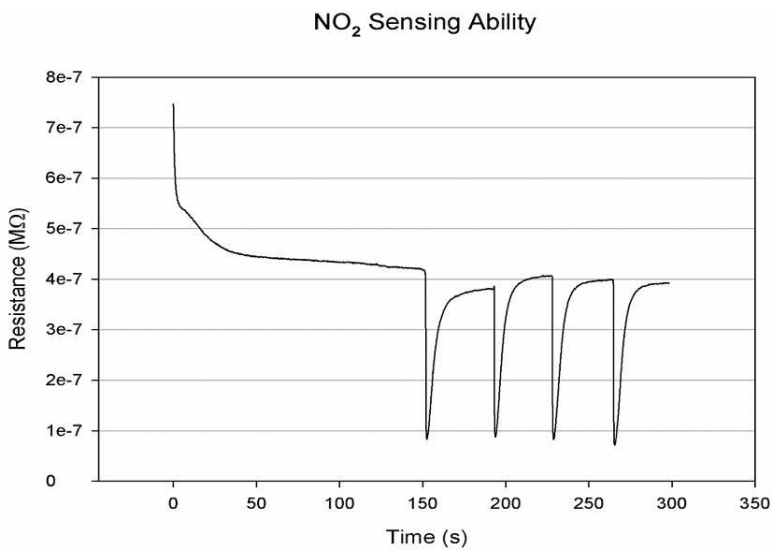

Fig. 4. $\mathrm{NO}_{2}$ Gas sensing ability of the sensor with nano-tetrapods.

Undoped $\mathrm{ZnO}$ is an n-type semiconductor and due to the fact that $\mathrm{NO}_{2}$ is an oxidizing gas, it accepts the electrons during a surface reaction [10]. This adsorption of $\mathrm{NO}_{2}$ results in an increment of the width of the surface charge layer [11]. This phenomenon causes the sensor resistance to increase, as can be seen in Fig. 4. Each time the $\mathrm{NO}_{2}$ gas was introduced into the system, the resistance had changed dramatically. Another point which is very important for the experiment, is that before and after the experiments no loss of nanowires' sensing ability was observed. The sensors were found do preserve all nanowires on their surface and the measurement could be taken nearly 50-60 times. During this entire period of time the information obtained from the sensors was correct and repeatable.

\section{Conclusions}

In the presented work we have produced a new sensor by using high-surface-area nano-tetrapods, using a five step method. The tetrapods were characterized in terms of their nanostructure, chemical composition, crystal structure and $\mathrm{NO}_{2}$ sensing mechanism. The crucial 
point of this work was making the sensor surface durable against the gas flow because of the low weight of the nanowires. We can say that the technique we have applied to nanowires to make them stay on the surface of the sensor worked well, and has allowed us to obtain meaningful data from the sensors, as can be seen from the measurement results.

\section{Acknowledgments}

This work was supported by the project sponsored by The Scientific and Technological Research Council of Turkey (TUBITAK — Grant No: 111M261).

\section{References}

[1] A.V. Emeline, G.V. Kataeva, A.V. Panasuk, V.K. Ryabchuk, N.V. Sheremetyeva, N. Serpone, J. Phys. Chem. B 109, 5175, (2005).

[2] M. Kroger, S. Hamwi, J. Meyer, T. Riedl, W. Kowalsky, A. Kahn, Org. Electron. 10, 932 (2009).
[3] J. Lee, M.C. Orilall, S.C. Warren, M. Kamperman, F.J. DiSalvo, U. Wiesner, Nat. Mater. 7, 222 (2008).

[4] H.J. Bolink, E. Coronado, J. Orozco, M. Sessolo, Adv. Mater. 21, 79 (2009).

[5] M. Li, L. Zhu, D. Lin, Environ. Sci. Technol. 45, 1977 (2011).

[6] N. Jones, B. Ray, K.T. Ranjit, A.C. Manna, Microbiol. Lett. 279, 71 (2008).

[7] J.F. Chang, H.H. Kuo, I.C. Leu, M.H. Hon, Sensor. Actuat. B: Chem. 84, 258 (2002).

[8] O. Lupan, S. Shishiyanu, L. Chow, T. Shishiyanu, Thin Solid Films 516, 3338 (2008).

[9] C.X. Xu, X.W. Sun, Z.L. Dong, M.B. Yu, Appl. Phys. Lett. 85, 3878 (2004).

[10] S.P. Yawale, S.S. Yawale, G.T. Lamdhade, Sensor. Actuat. A: Phys. 135, 388 (2007).

[11] M. Law, H. Kind, B. Messer, F. Kim, P.D. Yang, Angew. Chem. Int. Ed. 412405 (2002). 